\title{
Development and Validation of New High Performance Liquid Chromatography Analytical Technique For Separation of Diclofenac Sodium and Lidocaine Hydrochloride From Ampoule Injection
}

\author{
Mohammed Ali Salih \\ Chemistry Department \\ College of Science \\ University of Sulaimani \\ Sulaimani. Iraq \\ mohammed.ali@univsul.edu.iq
}

\author{
Dlivan Fattah Aziz \\ College of Pharmacy \\ University of Sulaimani \\ Sulaimani, Iraq \\ dlivan.aziz@univsul.edu.iq
}

Salar Ibrahim Ali

Nursing Department

Technical College of Health

Sulaimani Polytechnic University

Sulaimani, Iraq

salar.ali@spu.edu.iq

Article Info

Volume 5 - Issue 1 June 2020

DOI:

10.24017/science.2020.1.11

Article history:

Received: 01 April 2020

Accepted: 28 May 2020

\section{Keywords:}

Diclofenac sodium,

$\mathrm{HCl}$ lidocaine,

Reverse phase Higher performance

chrmomatography,

Simultaneous estimation

\section{ABSTRACT}

In the current investigation, a number of chromatographic methods with the accurate, precise and specific criteria have been developed and validated for diclofenac sodium and lidocaine hydrochloride Commitment of their large quantities ampule of pharmaceutical dosage form. The High-Performance Liquid Chromatography (HPLC) system was performed at $25{ }^{\circ} \mathrm{C}$; with appropriate chromatographic isolation accomplished through the use of Waters Symmetry SB-C7 column with a mobile phase containing $0.1 M$ sodium acetate and methanol (40:60) $(v / v)$. During development the portable stage was delivered at a stream rate of $1 \mathrm{~mL} / \mathrm{min}$, the wavelength was adjusted at $254 \mathrm{~nm}$. First of all, the retention times for diclofenac sodium and lidocaine $\mathrm{HCl}$ were about 4.1 and $10.8 \mathrm{~min}$ accordingly. A performance and technical demonstration of the suggested Revers phase-HPLC method has been numerically challenged with support to process appropriateness, verticality, scales, simplicity, repeatability, sensitivity, stability, discovery and limits of quantification. In addition, the calibration curves for diclofenac sodium active 


\begin{abstract}
pharmaceutical ingredient (API) with linear regressions > 0,999895 obtained linear in the distances 1870-5600 $\mu \mathrm{g} / \mathrm{mL}$. Moreover, for determining of lidocaine $\mathrm{HCl}$ drug, a range of 500 $1500 \mu \mathrm{g} / \mathrm{mL}$ of working standard was used, the result showed for lidocain $\mathrm{HCl}$ that a linear curve with correlation coefficients of > 0.99980. Finally, the both drugs were isolated and resolute with selective and stable characteristics by the proposed technique. In the conclusion, successful validation of the HPLC approach has been demonstrated with high precision and accuracy for the assessment of both the mixed dosage form type of both diclofenac sodium and lidocaine $\mathrm{HCl}$.
\end{abstract}

Copyright $(2020$ Kurdistan Journal of Applied Research. All rights reserved.

\title{
1. INTRODUCTION
}

Diclofenac sodium becomes considered part of derivative of phenyl acetic acid, as well as its chemical structure is shown in (Figure 1a) [1]. It has a number of medical importance, such as non-steroidal obviously pro-inflammatory reaction, It's also performed under different situations, such as rheumatoid arthritis, osteoarthritis and ligament illnesses and even in the prevention of endovascular eye miosis throughout glaucoma processing [2-33]. Lidocaine Hydrochloride has become a local anesthetic and the chemical name is hydrochloride 2(Diethylamino)-N-(2, 6- dimethylphenyl)-acetamide, its chemical structure is illustrated in (Figure 1b) [1, 34]. Lidocaine has a medical importance in using for local anesthesia and its mechanism of action is stopping the nerve signals between nerves in the body, which leads to cause a temporary numbness and a loss of skin and mucous membranes' feeling [2].

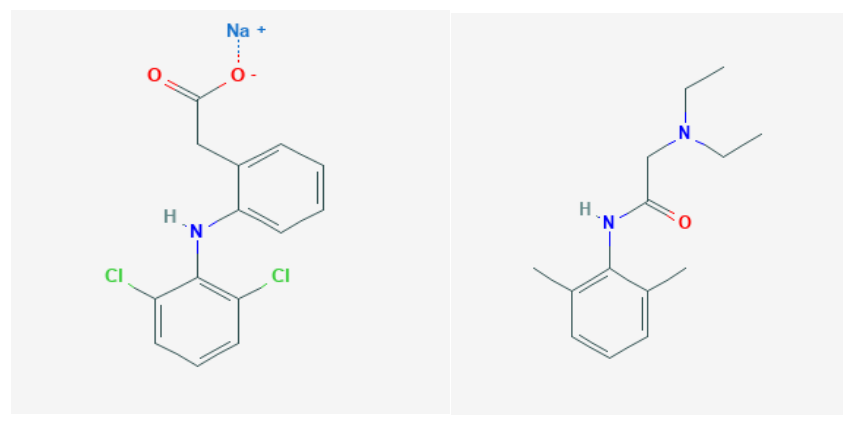

(a)

(b)

Figure 1: Compound composition for (a) Diclofenac sodium [1] (b) Lidocaine hydrochloride [34]

A combined dosage form of both diclofenac sodium and lidocaine $\mathrm{HCl}$ had been formulated, under the name of Olfen ampoules which is available worldwide. The medical importance of the combination form is that the administration of Olfen injections shows a low pain at site of injection and also a better local tolerance [1]. According the literature review on both drug in both the United Kingdom and the United States, analysis of raw material of diclofenac sodium is performing by Pharmacopoeias through using a special method, which is known as potentialometric un-aqueous serial dilutions and that its medication combination dosage forms are determining mostly by reversed phase HPLC (RP- HPLC) technique [1, 3, 4]. Diclofenac 
sodium with other drugs were also identified using various techniques, including Uvspectrophotometrics [1,5,6,7,8,9], multivariate calibration [10], spectrofluorometric [11,12], TLC- Densitometry $[1,13,14,15]$, HPLC $[16,17,18,19]$, Electrophoretic capillary methods[20,21], and electrical and chemical techniques [1]. Furthermore, for assessment of lidocaine $\mathrm{HCl}$ in its powder and dosage forms, a number of suggested techniques are using by all other the British Pharmacopeia and the United State Pharmacopeia companies. Moreover, titrimetric method is mostly used by British Pharmacopoeia for powder form of lidocaine $\mathrm{HCl}$ while for evaluation of lidocaine $\mathrm{HCl}$ in the ointment form HPLC method was applied. However, in the United States pharmacopeia monograph HPLC seems to be a successful technique for estimating of lidocaine throughout powder structure whereas for analyzing dosage forms and semisolid topical arrangements titrimetric method seems more efficient [1, 3]. Various techniques were utilized for lidocaine $\mathrm{HCl}$ for example UV-visible spectrophotometer [23], multivariate calibration [2], Gas Chromatography [25], Thin Layer Chromatography Densitometry [1], Revers-phase higher performance chromatography [22, 23] and capillary electrophoretic techniques [1]. Lidocaine $\mathrm{HCl}$ and Diclofenac sodium are examined by two turned around stage HPLC techniques for the synchronous assurance of diclofenac sodium and lidocaine in two-fold blend and pharmaceutical definition [1]. The proposed techniques have the advantage of less time consuming and cost over the distributed HPLC techniques; therefore, there is no requirement for high cost instruments or chemicals [1].

\section{METHODS AND MATERIALS}

Determination of Lidocaine $\mathrm{HCl}$ and Diclofenac sodium by reverse phase HPLC (waters alliance 2695 HPLC system)

For determination of lidocaine $\mathrm{HCl}$ and diclofenac $\mathrm{Na}$, the HPLC-Diode array detector approach has been applied, which has the following characteristics such as waters alliance 2695 HPLC system USA, the auto-sampler injection system, Flush Qua ternary, de-gassing dryer and array group, but rather numerous frequency finders 2487 UV-Visible or 996 Photodiode array detector, The $2487 \mathrm{UV}-\mathrm{Visible}$ detector is considered as the greatest sensitive and flexible absorbance detector which is available for HPLC. Moreover, it has a quality advanced programmability, dual wavelength capacity, un-matchless signal-to-noise performance, decreased optical band width, and unusual linearity associated with a PC stacked with Empower Software. The column of Waters Symmetry was used to evaluate both analytes, C7-RP-HPLC column 4.6 x $150 \mathrm{mmf}$ column. The injection volume was injected a $20 \mu \mathrm{l}$ loop. Mobile phase filtrated by Millipore Swinnex filter $0.45 \mu \mathrm{m}$ particle size. A type of higher performance liquid chromatography is called Waters, system 2487 different with the parameter Ultraviolet absorption coefficient detector and the Waters 2695 plus auto-sampler were utilized individually like a mobile phase at flow $1 \mathrm{ml} / \mathrm{min}$,As well as the latter retention moment of lidocaine $\mathrm{HCl}$ is a $4.1 \pm 0.5 \mathrm{~min}$ and $10.8 \pm 0.5 \mathrm{~min}$ for lidocaine $\mathrm{HCl}$. Degassing was accomplished through Ventilation via a $0.45 \mu \mathrm{m}$ pore size thickness channel and bubble prevention its do sonication. Worked on auto sample and column heat at $25^{\circ} \mathrm{C}$, using wavelength detector at $254 \mathrm{~nm}$.

Diclofenac sodium and Lidocaine $\mathrm{HCl}$ were applied by medical Pioneer Company for pharmaceutical in Sulaimani province, Kurdistan Region of Iraq. The purity was found or analsying by pioneer co at $99.9 \%$ and $99.7 \%$ for diclofenac sodium and lidocaine $\mathrm{HCl}$ respectively according to analyzing method by pioneer company. Olfen 75 IM ampules (Batch No. T13415A) every ampule categorized which contains two actives with different concentration $75 \mathrm{mg} / 2 \mathrm{ml}$ for diclofenac sodium and $20 \mathrm{mg} / \mathrm{ml}$ for lidocaine $\mathrm{HCl}$ respectively produced by Mepha Pharmaceutical readiness. The chemical materials used for preparation mobile phase is Methanol analytical grade and sodium acetate manufactured by sigma-Aldrich and deionized water refined utilizing a Milli-Q Reagent Grade water system were used as a drug solvents. At the concentration of $1 \mathrm{mg} / \mathrm{ml}$ for lidocaine and $3.75 \mathrm{mg} / \mathrm{ml}$ for diclofenac sodium, standard solution of diclofenac $\mathrm{Na}$ and lidocaine HCL was fully prepared in the 
moving phase.

\section{Applied method and investigation of ampule Measurement types}

A substance of 10 Olfen ampules has been correctly combined and exactly measured quantity of $2.0 \mathrm{ml}$ proportionate to $20.0 \mathrm{mg}$ Lidocaine and $75.0 \mathrm{mg}$ of Diclofenac sodium changed into exchanged dissolve and make a full a $50 \mathrm{ml}$ volumetric flask by mobile phase it's the technique of every strategy was followed and the centralization of Diclofenac sodium and Lidocaine Hydrochloride was determined from the comparing relapse condition. The Reverse phase -HPLC Technique for The Diclofenac sodium and Lidocaine Chloride became accredited in term of precision, reproducibility, linearity, specificity, Constrain of Discovery (LOD), Constrain of Measurement (LOQ), and power concurring to ICH Harmonized Tripartite Rules [30].

The framework suitability was evaluated by six duplicate investigations of Diclofenac sodium and Lidocaine $\mathrm{HCl}$ at a concentration of $3.75 \mathrm{mg} / \mathrm{ml}$ and $1.0 \mathrm{mg} / \mathrm{ml}$. The acknowledgment foundation was $\pm 2 \%$ within the peak range and maintenance time for diclofenac sodium and lidocaine $\mathrm{HCl}$ was for relative standard deviation present. The HPLC Reversing Phase technique was assessed to make which the ingredients. Given in the details were not interfered with. A particularity became concentrated by another infusion of ingredients.

Linearity is considered as the capacity to acquire the results of the test which are straight forwardly relative to the grouping of the materials; furthermore, linearity is normally controlled by three injections of five different concentrations of diclofenac sodium and lidocaine $\mathrm{HCl}(50,75,100,125$ and $150 \mathrm{mg} / \mathrm{ml})$ and then the normal top regions were plotted against the concentrations. At that point, the linearity is assessed by utilizing the calibration bend in order to calculate the coefficient of relationship, which is included incline and captured. In common, an esteem of the relationship coefficient that are more than 0.999; therefore, it is considered as the proof of a satisfactory fit for the information to the relapse line. Moreover, the precision of an explanatory strategy communicates the closeness between the anticipated esteem and the measured esteem. This is achieved through measuring a basis points recovery ( $\mathrm{R}$ percent) of the recovered eluent. Therein example, to assess the accuracy of the created technique, progressive examination three diverse concentrations one less than in the real concentration of $75 \mathrm{mg} / \mathrm{ml}$ and $100 \mathrm{mg} / \mathrm{ml}$ and one more than the actual concentration of $125 \mathrm{mg} / \mathrm{ml}$ of Diclofenac sodium and Lidocaine $\mathrm{HCl}$ standard was achieved using the strategy developed. In addition, the information of the test was measurably examined by utilizing the equation \% Recuperation $=($ Recuperated conc. $/$ Infused conc. $) \times 100$, which to be considered as the recuperation and legitimacy of the created strategy. The acknowledged cruel recuperation ought to be inside $98-102 \%$.

The precision of a quantifiable method is defined as the level of understanding between individual tests, whenever the method of evaluating different imitates is drearily linked of three distinctive events. First, the intraday accuracy was examined by assessing the measurement curves of six duplicates of distinctive inter-day accuracy concentrations by analyzing six replicates of different Diclofenac sodium and Lidocaine $\mathrm{HCl}$ concentrations. Its three different days. Moreover, the technique's complete precision was communicated like RSD. Six imitate examinations at the accumulation of $120 \mu \mathrm{g} / \mathrm{ml}$ of conventional diclofenac sodium and lidocaine $\mathrm{HCl}$ have decided on precision within the current strategy improvement and approval convention arrangement utilizing the created strategy and \% RSD $\leq 2 \%$ was acknowledged.

The Detection limit smallest quantity of a substance which may be distinguished by a stated confidence level from the absence of that substance. Quantification limit would be the lowest intensity of analyte which could be corrected with satisfactory sensitivity and specificity. In the current investigation, those other two variables are quantified using the equation limit of detection $=3.3 \mathrm{Signal} / \mathrm{Noise}$ equal to $0.76 \mathrm{mg} \mathrm{mL}^{-1}$ for diclofenac sodium and $1.23 \mathrm{mg} \mathrm{ml}$ ${ }^{1}$ for Lidocaine $\mathrm{HCl}$ but quantification limit $=10(\mathrm{Sy} / \mathrm{S}) 1.8 \mathrm{mg} \mathrm{mL}^{-1}$ Diclofenac sodium and $0.5 \mathrm{mg} \mathrm{mL} \mathrm{m}^{-1}$ for Lidocaine $\mathrm{HCl}$ conventional reaction variation (crest zone) and $\mathrm{S}=$ calibration bend inclination. [28, 29]. 


\section{RESULTS}

\section{Linearity of Diclofenac Sodium by HPLC}

For determination of linearity of diclofenac sodium-HPLC, the linearity of diclofenac sodium was performed as explained in experimental part and then the average area was calculated by average of three repeat measurements. The slope was 7806.183, intercept 648427.1, correlation (r) 0.999956 and coefficient of correlation $\left(\mathrm{r}^{2}\right) 0.9999$ (Table 1). The normal top zones were graphed toward their intensity with the esteem of relationship coefficient $\left(R^{2}\right)$ 0.99991 and are viewed as the prove of the satisfactory wellness for the information to the relapse line (Figure 2).

Table 1: Linearity of Lidocaine $\mathrm{HCl}$

\begin{tabular}{|c|c|c|c|c|c|}
\hline $\begin{array}{l}\text { Nomina } \\
\text { l value }\end{array}$ & $\begin{array}{c}\text { Concentratio } \\
\mathrm{n}(\mu \mathrm{g} / \mathrm{mL})\end{array}$ & Area & $\begin{array}{c}\text { Average } \\
\text { Area }\end{array}$ & & \\
\hline \multirow[t]{3}{*}{$50 \%$} & \multirow[t]{3}{*}{1873.03} & 15210882.02 & \multirow[t]{3}{*}{15209917.33} & Slope & 7806.183 \\
\hline & & 15202169.14 & & intercept & 648427.1 \\
\hline & & 15216700.82 & & $\mathrm{r}$ & 0.999956 \\
\hline \multirow[t]{3}{*}{$75 \%$} & \multirow[t]{3}{*}{2809.55} & 22540196.68 & \multirow[t]{3}{*}{22543897.99} & \multirow[t]{3}{*}{$\overline{\mathrm{R}^{2}}$} & \multirow[t]{3}{*}{0.9999} \\
\hline & & 22547073.83 & & & \\
\hline & & 22544423.47 & & & \\
\hline \multirow[t]{3}{*}{$100 \%$} & \multirow[t]{3}{*}{3746.06} & 30117886.55 & \multirow[t]{3}{*}{30013805.43} & & \\
\hline & & 29975982.72 & & & \\
\hline & & 29947547.02 & & & \\
\hline \multirow[t]{3}{*}{$125 \%$} & \multirow[t]{3}{*}{4682.58} & 37313342.26 & \multirow[t]{3}{*}{37303518.88} & & \\
\hline & & 37316040.81 & & & \\
\hline & & 37281173.56 & & & \\
\hline \multirow[t]{3}{*}{$150 \%$} & \multirow[t]{3}{*}{5619.09} & 44368608.9 & \multirow[t]{3}{*}{44383143.93} & & \\
\hline & & 44385628.88 & & & \\
\hline & & 44395194 & & & \\
\hline
\end{tabular}




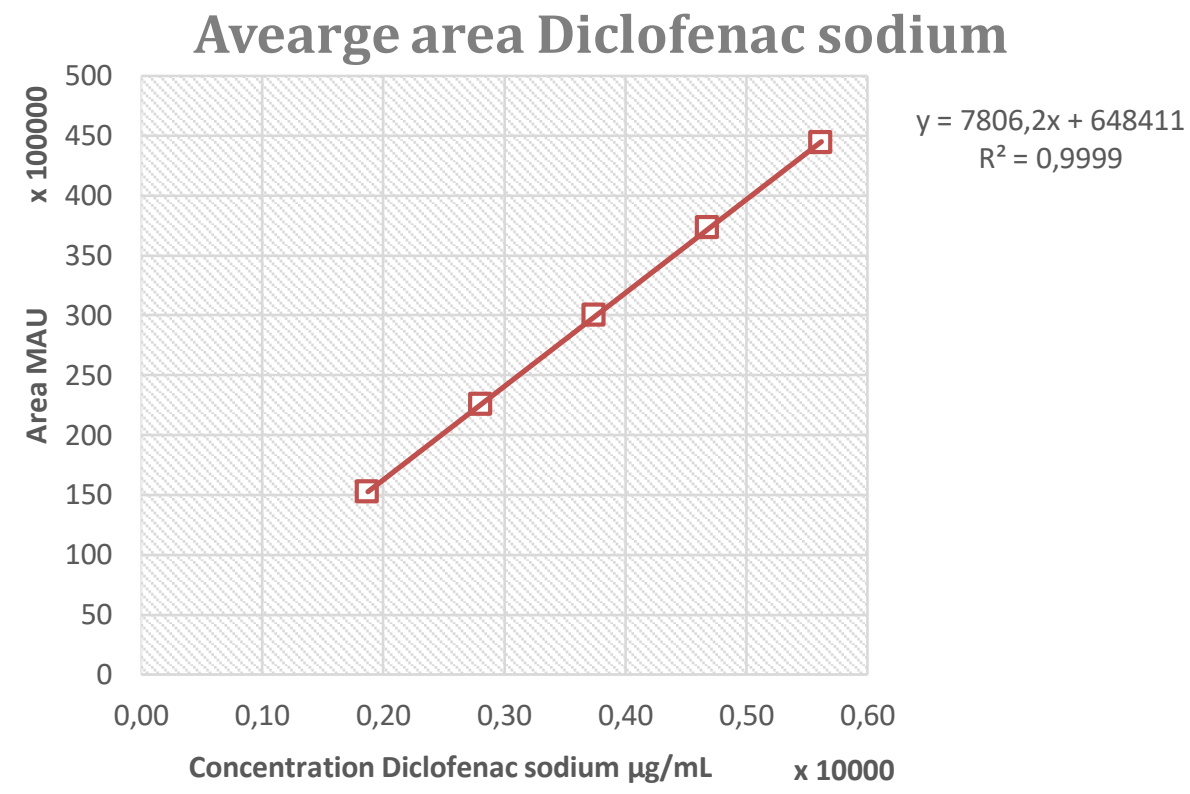

\section{Linearity of Lidocaine $\mathrm{HCl}$ by HPLC}

For determination of linearity of lidocaine $\mathrm{HCl}$ by HPLC, three injections of five different concentrations of lidocaine $\mathrm{HCl}$ were as explained in experimental part and then the average area was calculated by average of three repeat measurements. The slope was 899.0516, intercept -1635.7, correlation (r) 0.999996 and coefficient of correlation $\left(\mathrm{r}^{2}\right) 1.0000$ (Table 2). The normal peak areas were scheme opposed to their concentrations with the value of correlation coefficient $\left(r^{2}\right) 0.99999$ and therefore, it is revealed as the evidence of the accepted fitness of the data to the regression line (Figure 3)

Table 2: Linearity of Lidocaine $\mathrm{HCl}$

\begin{tabular}{|c|c|c|c|c|c|}
\hline $\begin{array}{l}\text { Amount } \\
\text { added } \\
(\%)\end{array}$ & $\begin{array}{l}\text { Nominal value } \\
\qquad\left(\mu \mathrm{g} \mathrm{mL} \mathrm{L}^{-1}\right)\end{array}$ & Area & Average area & & \\
\hline \multirow[t]{3}{*}{$50 \%$} & \multirow[t]{3}{*}{500.06} & 448665.401 & \multirow[t]{3}{*}{449123.4043} & Slope & 899.0516 \\
\hline & & 449853.626 & & intercept & -1635.7 \\
\hline & & 448851.186 & & $\mathrm{r}$ & 0.999996 \\
\hline \multirow[t]{3}{*}{$75 \%$} & \multirow[t]{3}{*}{750.09} & 671495.658 & \multirow[t]{3}{*}{671506.425} & \multirow[t]{3}{*}{$\overline{\mathrm{R}^{2}}$} & \multirow[t]{3}{*}{1.0000} \\
\hline & & 671174.927 & & & \\
\hline & & 671848.69 & & & \\
\hline \multirow[t]{3}{*}{$100 \%$} & \multirow[t]{3}{*}{1000.12} & 899508.215 & \multirow[t]{3}{*}{896678.8663} & & \\
\hline & & 894876.632 & & & \\
\hline & & 895651.752 & & & \\
\hline \multirow[t]{3}{*}{$125 \%$} & \multirow[t]{3}{*}{1250.15} & 1123823.873 & \multirow[t]{3}{*}{1122981.359} & & \\
\hline & & 1122796.333 & & & \\
\hline & & 1122323.871 & & & \\
\hline \multirow[t]{3}{*}{$150 \%$} & \multirow[t]{3}{*}{1500.18} & 1345989.523 & \multirow[t]{3}{*}{1347336.949} & & \\
\hline & & 1347425.014 & & & \\
\hline & & 1348596.311 & & & \\
\hline
\end{tabular}




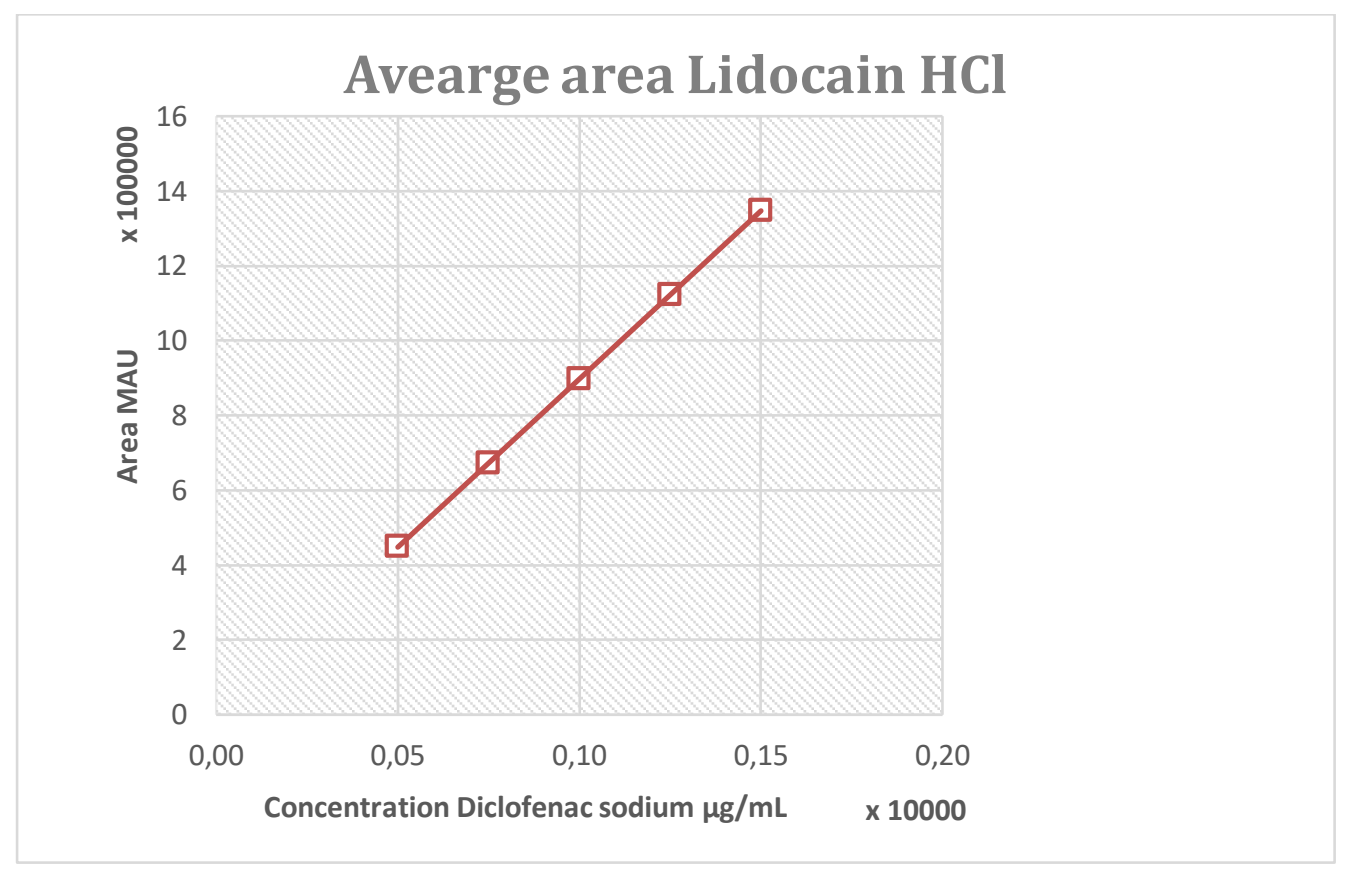

\section{Determination and Recovery of Diclofenac Sodium and Lidocaine $\mathrm{HCl}$}

Accuracy of an explanatory strategy communicates with the closeness of understanding between the arrangements of estimations acquired from numerous testing of the same homogeneous test beneath the endorsed conditions. For determination of accuracy, the placebo was prepared placebo in accordance to Olfen without both Diclofenac sodium and Lidocaine hydrochloride. The excipients contain (Acetylcysteine, Edetate sodium, propylene glycol, polyethylene glycol, sodium hydroxide, water for injection). The result shows that in repeatability, Percent Comparative standard error of diclofenac sodium peak area concentration of $75 \%, 100 \%$, and $125 \%$ was found to be $0.16 \%, 0.43 \%$, and $0.02 \%$, respectively [Table 3]. Furthermore, a percent Compared standard error of lidocaine $\mathrm{HCl}$ peak region standard concentration of $75 \%, 100 \%$, and $125 \%$ was found to be $0.04 \%, 0.22 \%$, and $0.16 \%$ respectively [Table 4]. The result revealed that this precision that presented with $\%$ RSD values are less than $1.0 \%$; therefore, the mentioned method is considered to be a highly precise and reproducible. Moreover, the verification of its technical method was the system of showing the suitability of the quantitative procedure with its original purpose. Consequently, the data collected from the verification strategy experiment may be used to measure the performance, efficiency and coherence of the analysis outcomes. The current higher performance liquid chromatography technique for evaluating diclofenac sodium has been developed and validated. In which, several mobile phase compositions were tested, and satisfactory segregation became achieved used the composition of sodium acetate in the mobile phase: methanol (A: B): (40:60 v/v). An optimized chromatogram of blank, standard, and sample was shown in Figure 1. The retention time (RT) of diclofenac sodium and lidocaine $\mathrm{HCl}$ peak was found to be at $4.022 \mathrm{~min}$ and $11.166 \mathrm{~min}$, respectively [Figure 4]. The chromatogram of the sample Olfen is also shown in [Figure 5]. 
Table 3: Determination of diclofenac sodium recovery

\begin{tabular}{|c|c|c|c|c|c|c|}
\hline \multicolumn{7}{|c|}{ Standard Data } \\
\hline $\begin{array}{c}\text { Concentratio } \\
n(\mu \mathrm{g} / \mathrm{mL})\end{array}$ & \multicolumn{2}{|c|}{ Area } & Average area & SD & \multicolumn{2}{|c|}{ RSD\% } \\
\hline 3746.730 & \multicolumn{2}{|c|}{28899069} & 28999684.2000 & 60018.64 & \multicolumn{2}{|c|}{$0.2 \%$} \\
\hline & \multicolumn{2}{|c|}{29025203} & & & & \\
\hline & \multicolumn{2}{|c|}{29025427} & & & & \\
\hline & \multicolumn{2}{|c|}{28994749} & & & & \\
\hline & \multicolumn{2}{|c|}{29053973} & & & & \\
\hline \multicolumn{7}{|c|}{ Accuracy - recovery of Diclofenac Sodium } \\
\hline $\begin{array}{c}\text { Nominal } \\
\text { value }\end{array}$ & $\begin{array}{c}\text { Amount } \\
\text { spiked } \\
(\mu \mathrm{g} / \mathrm{mL})\end{array}$ & Area & $\begin{array}{c}\text { Amount } \\
\text { recovered } \\
(\mu \mathrm{g} / \mathrm{mL})\end{array}$ & $\begin{array}{c}\% \\
\text { recovery }\end{array}$ & $\begin{array}{l}\text { Average } \\
\text { Recovery }\end{array}$ & $\begin{array}{c}\text { \%RS } \\
\text { D }\end{array}$ \\
\hline \multirow[t]{3}{*}{$75 \%$} & \multirow{3}{*}{2810.05} & 22002225 & 2842.66 & $101.16 \%$ & \multirow[t]{3}{*}{$100.98 \%$} & \multirow[t]{3}{*}{$0.16 \%$} \\
\hline & & 21938461 & 2834.43 & $100.87 \%$ & & \\
\hline & & 21945833 & 2835.38 & $100.90 \%$ & & \\
\hline \multirow[t]{3}{*}{$100 \%$} & \multirow[t]{3}{*}{3746.73} & 29282025 & 3783.21 & $100.97 \%$ & \multirow[t]{3}{*}{$100.52 \%$} & \multirow[t]{3}{*}{$0.43 \%$} \\
\hline & & 29137890 & 3764.59 & $100.48 \%$ & & \\
\hline & & 29033890 & 3751.15 & $100.12 \%$ & & \\
\hline \multirow[t]{4}{*}{$125 \%$} & \multirow[t]{3}{*}{4683.41} & 36161668 & 4672.05 & $99.76 \%$ & \multirow[t]{3}{*}{$99.77 \%$} & \multirow[t]{3}{*}{$0.02 \%$} \\
\hline & & 36174515 & 4673.71 & $99.79 \%$ & & \\
\hline & & 36167094 & 4672.75 & $99.77 \%$ & & \\
\hline & & Average & & & $100.42 \%$ & \\
\hline
\end{tabular}

Table 4: Determination recovery of lidocaine $\mathrm{HCl}$

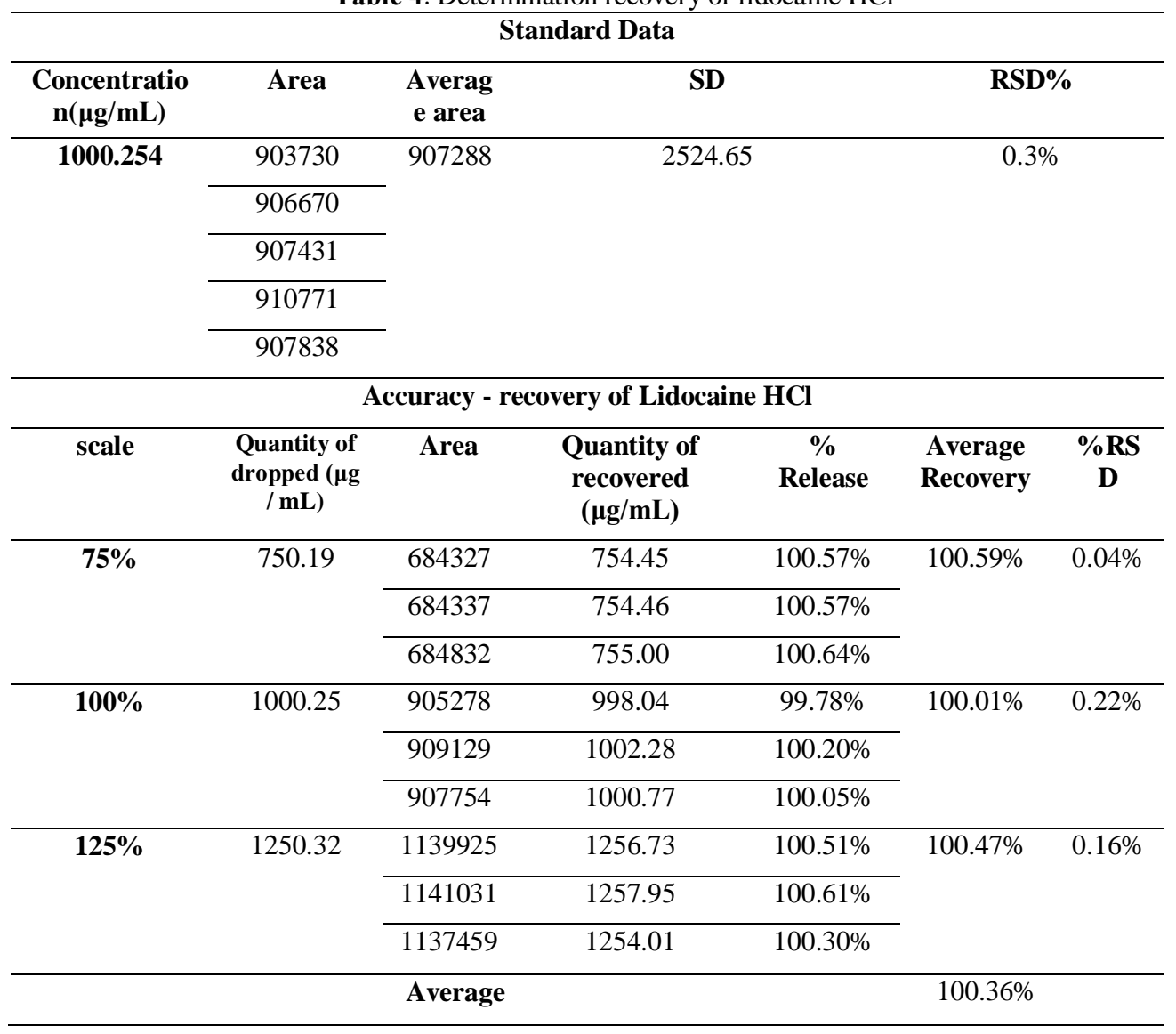




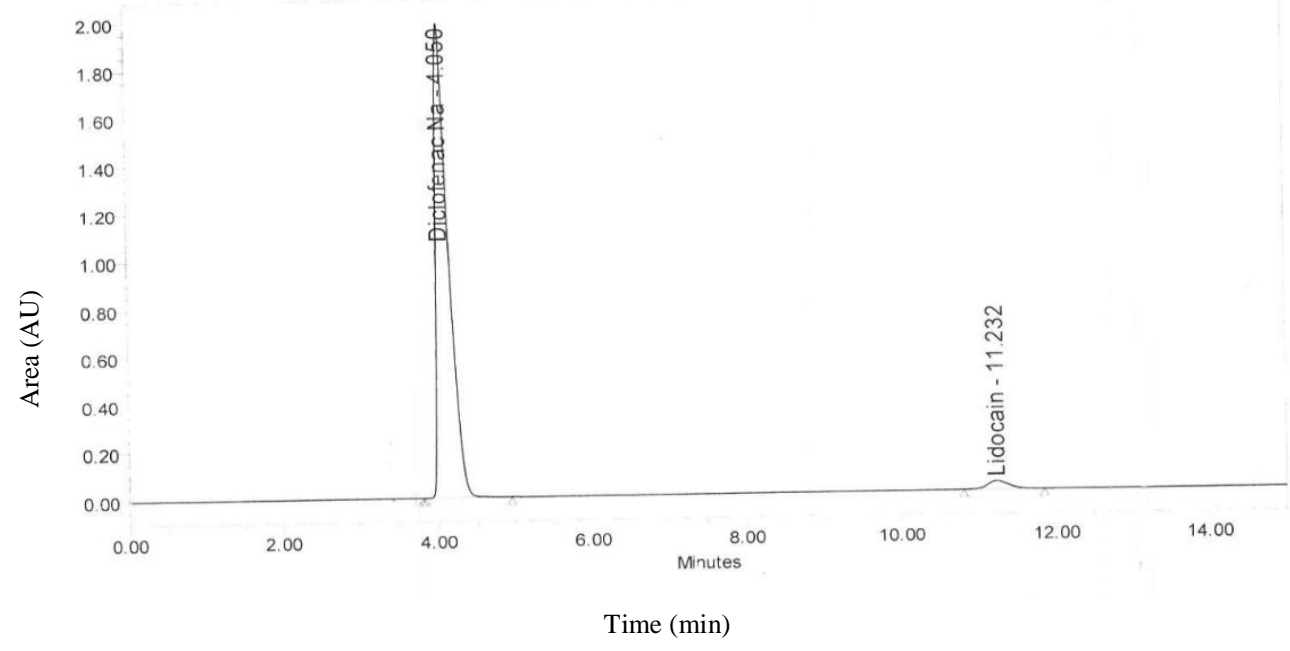

Figure 4: HPLC chromatogram of combination of both Standard diclofenac sodium $3.75 \mathrm{mg} / \mathrm{ml}$ and lidocaine $\mathrm{HCl} 1 \mathrm{mg} / \mathrm{ml}$ at $254 \mathrm{~nm}$.

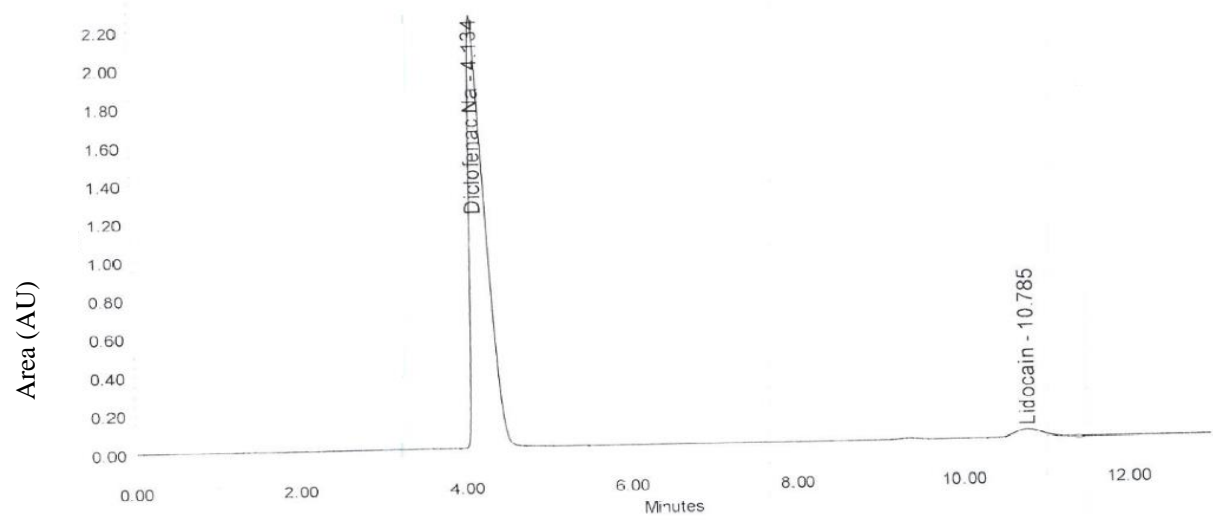

Time (min)

Figure 5: HPLC chromatogram of Sample Olfen contain $3.75 \mathrm{mg} / \mathrm{ml}$ Diclofenac sodium and 1mg / $\mathrm{ml}$ lidocaine $\mathrm{HCl}$ at $254 \mathrm{~nm}$. 


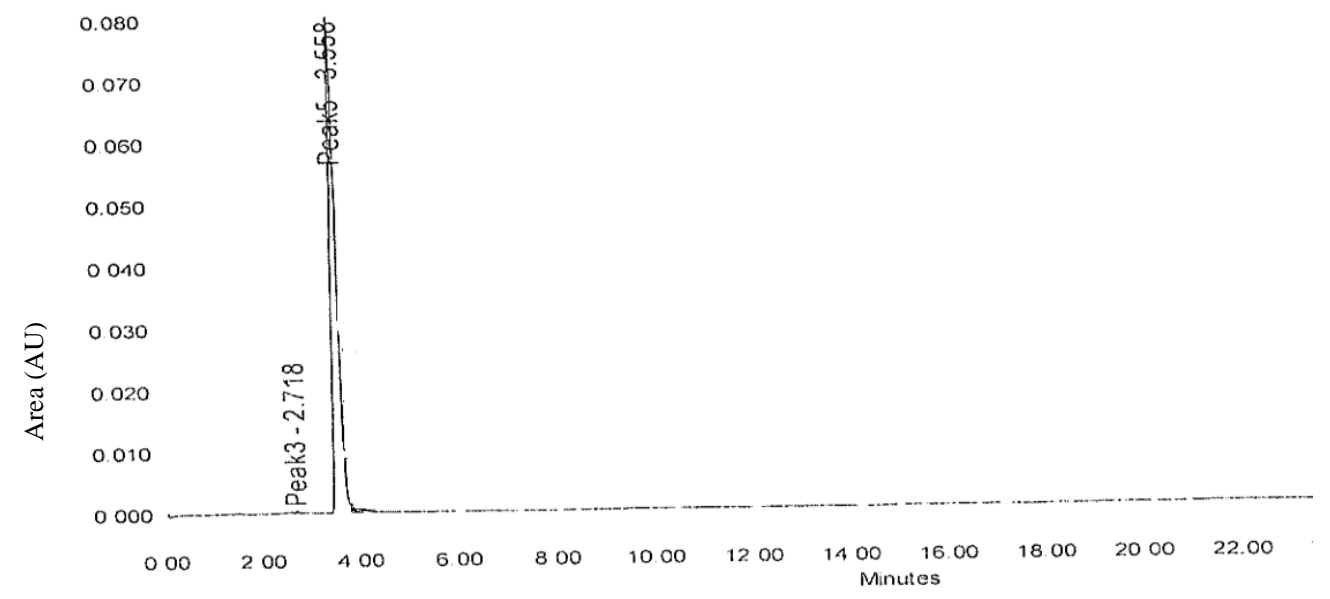

Figure 6: Chromatogram of placebo solution showing no interference.

Time (min)

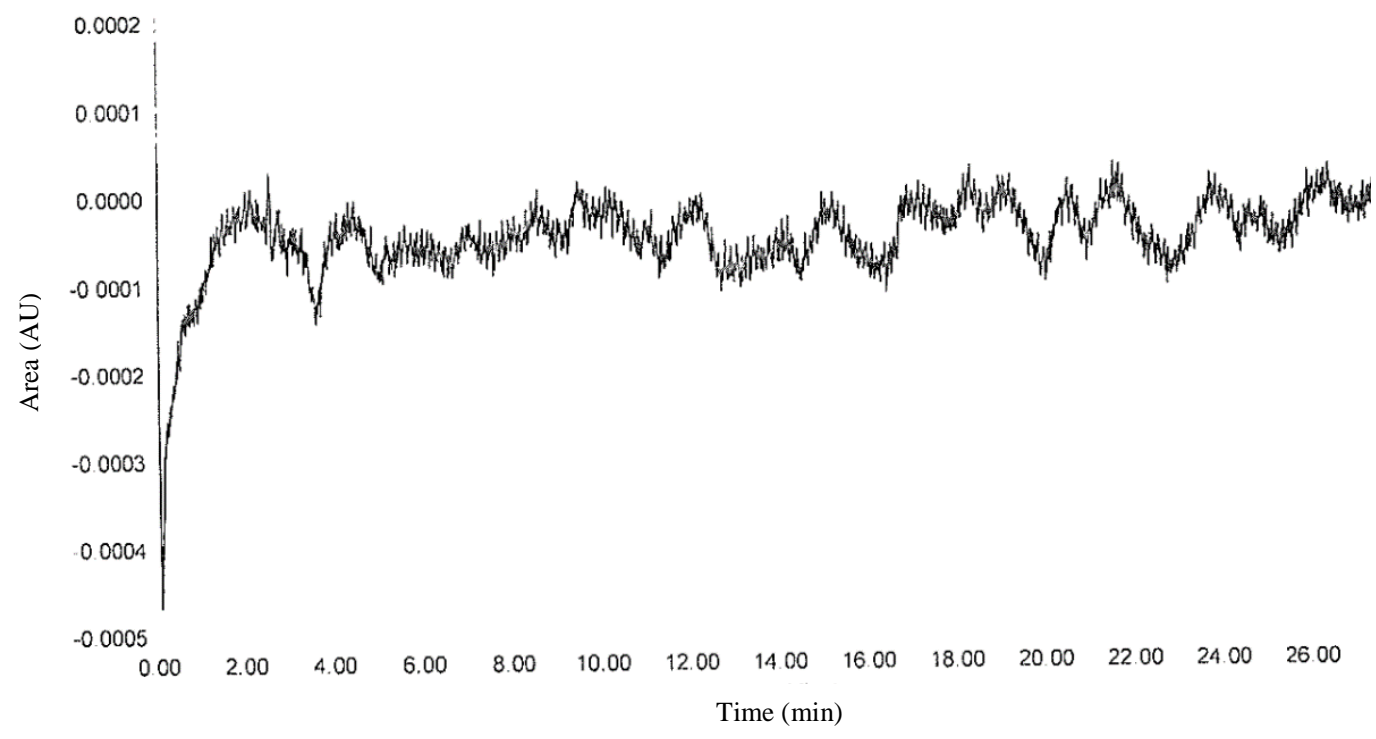

Figure 7: Chromatogram of the diluent.

\section{Precision of diclofenac sodium and lidocaine $\mathrm{HCl}$ and accuracy}

Three concentration degrees for both Diclofenac sodium and Lidocaine $\mathrm{HCl}$ used three imitate judgments for each concentration within one day were considered in under-day precision and accuracy for the project strategy. Essentially, the precision and consistency between the days were checked by assessing a certain three concentrations for each Diclofenac sodium and lidocaine $\mathrm{HCl}$ usage of three rehashed decisions imitate for several days. Using the comparable relapse conditions, recoveries were measured, and they were palatable. The absolute deviation rate and absolute blunder rate (Error percent) cannot exceed 2.0 percent, showing the high accuracy and accuracy of the strategy generated to estimate the part in its bulk frame (Table 5). 
Table 5: Commitment of the sodium diclofenac and lidocaine $\mathrm{HCl}$ mixture utilizing the approved

\begin{tabular}{|c|c|c|c|c|c|c|}
\hline \multicolumn{7}{|c|}{ Revers phase-HPLC process. } \\
\hline Compound & $\begin{array}{l}\text { Analytical } \\
\text { Form }\end{array}$ & Level & $\begin{array}{c}\text { Fractional } \\
\text { mean }(\mu \mathrm{g} / \mathrm{ml})\end{array}$ & $\begin{array}{c}\text { Discovered } \\
\pm \mathrm{SD}(\mu \mathrm{g} / \mathrm{ml})\end{array}$ & $\begin{array}{c}\text { relative } \\
\text { standard } \\
\text { deviation } \\
\%\end{array}$ & $\begin{array}{c}\text { Error } \\
\%\end{array}$ \\
\hline \multirow[t]{6}{*}{ Diclofenac Na } & \multirow[t]{3}{*}{ Within-day } & $75 \%$ & 2.810 & $2.8402 \pm 0.21$ & 0.20500 & $\begin{array}{l}-1.07 \\
\end{array}$ \\
\hline & & $100 \%$ & 3.750 & $3.771 \pm 0.457$ & 0.18100 & -0.56 \\
\hline & & $125 \%$ & 4.680 & $4.672 \pm 1.174$ & 0.08000 & 0.1709 \\
\hline & \multirow[t]{3}{*}{ Between-day } & $75 \%$ & 2.810 & $2.8404 \pm 0.156$ & 0.15600 & $\begin{array}{c}- \\
1.0819\end{array}$ \\
\hline & & $100 \%$ & 3.750 & $3.757 \pm 0.181$ & 0.45400 & $\begin{array}{c}- \\
0.1867\end{array}$ \\
\hline & & $125 \%$ & 4.680 & $4.669 \pm 4.16$ & 0.08900 & 0.235 \\
\hline \multirow[t]{6}{*}{ Lidocaine $\mathrm{HCl}$} & \multirow[t]{3}{*}{ Within-day } & $75 \%$ & 0.75019 & $\begin{array}{c}0.75445 \pm 0.00 \\
8\end{array}$ & 0.15 & $\begin{array}{c}- \\
0.5679\end{array}$ \\
\hline & & $100 \%$ & 1.003 & $1.002 \pm 0.003$ & 0.30004 & 0.099 \\
\hline & & $125 \%$ & 1.250 & 1.2574 & 0.00960 & -0.592 \\
\hline & \multirow[t]{3}{*}{ Between-day } & $75 \%$ & 0.75019 & $\begin{array}{c}0.75656 \pm 0.00 \\
2\end{array}$ & 0.25000 & -0.849 \\
\hline & & $100 \%$ & 1.003 & 1.0008 & 0.04600 & 0.21 \\
\hline & & $125 \%$ & 1.250 & 1.2558 & 0.06380 & -0.464 \\
\hline
\end{tabular}

${ }^{\mathrm{a}}$ Mean \pm standard deviation for three determinations.

\section{DISCUSSION}

Olfen ampoule is available in Kurdistan region pharmacies markets and it is widely used to treat different kind of pains. The analysis of this injection till today is not available in the United States pharmacopeia, British pharmacopeia and not even in Indian pharmacopeia. The combination of diclofenac sodium and lidocaine $\mathrm{HCl}$ injection was assessed by using reversed-phase HPLC-DAD in as it were one past distribution [24]. The distributed system included the application of the thermos scientific octadecasilane column as well as a flexible isocratic process consisting $80 \%$ of methanol, $20 \%$ of water and $0.01 \%$ corrosive acid [24]. Its past consideration did not illustrate the strategy's specificity and allow the two analytes to be determined from their associated compounds and objects of restricted- corruption [35]. Can resolve that shortcoming, a modern Revers-phase HPLC expository strategy was created and approved for assurance of both diclofenac sodium and lidocaine $\mathrm{HCl}$ and also to Solid specific flexibility-showing- investigation and performance certainty for diclofenac sodium with lidocaine $\mathrm{HCl}$ blend. Its foremost imperative viewpoint within the $\mathrm{LC}$ strategy advancement is the accomplishment of adequate determination with satisfactory alignment of the crest at sensible examination moment. And accomplish such purpose, HPLC - DAD $254 \mathrm{~nm}$ procedure in their combined pharmaceutical dosage form for assaying DC and LD. The minimal requirement of organic solvents demonstrated simplicity as water was used as a solvent for the preparation of working standard and sample solutions. That indicates that the approach proposed is cost-effective and environmentally friendly. Similarly, different from the universal UV detector $280 \mathrm{~nm}$ used in the previously published HPLC method [35]. , 
numerous studies are performed to improve as well as the fixed stages and the portable stages [35] and between the two materials with a fruitful determination of two components from the tried related substances and subsequently it was utilized in this consider [35].The mobile phase consisted of $0.1 \mathrm{M}$ sodium acetate and methanol and column different from the previously published HPLC method [35]. Based on the broad run approach both diclofenac sodium and lidocaine $\mathrm{HCl}$ and also lead to the disadvantages of the past distributed strategies for settling the combined combination. Therefore, the current investigation aims to create and approve an exact, delicate and specific spectrophotometric method and HPLC procedure for measuring diclofenac sodium and lidocaine $\mathrm{HCl}$ in a mixture detailing in the absence of planning or handling the test.

To evaluate the accuracy of the reversed-phase HPLC-UV System. A recovery experiments were performed on three representative standards and two commercial drug samples. And then standard additions method (Figure 5) was used for all of these determinations in order to avoid all the possible interferences [25, 26].

Method consistency was recorded as a percentage of relative standard deviation, and was calculated by evaluating reproducibility (internal-day measure) for 6 duplicate injections across all lidocaine- $\mathrm{HCl}$ concentrations. Also, the medium sensitivity (internal-day variety) was also tested over twice days utilizing an appropriate lidocaine- $\mathrm{HCl}$ concentration solution. The Intra-day average recoveries were in the range (96-100) and Inter- day average recoveries (93-100), which thought to be an acceptable result [27].

\section{CONCLUSION}

In conclusion, the modern reverse phase higher performance liquid chromatography (HPLC) technique is an easy, quick, clearly, accurately, and broadly acknowledged, and it is suggested for productive tests in a schedule work and also as a release reason within the quality control. In this manner, the strategy was demonstrated to be appropriate for diclofenac sodium and lidocaine $\mathrm{HCl}$ determination. Further explorations are needed to investigate the standardization of each individual compound separately. Therefore, this considers a depicted, selective dependable reverse-phase HPLC strategy, factual examination demonstrates that the strategy is reasonable for both component in dosage form straightforwardness was outlined by minimum utilized a dissolvable for arrangement of working standard a test arrangement.

\section{REFERENCE}

[1] Sweetman, S.C. ed., 2009. Martindale: the complete drug reference (Vol. 3709). London: Pharmaceutical press.

[2] M. Abdelrahman, M. Adly, W. Ali, S. Abdelwahab, "Development and Validation of Different Spectrophotometric and High-Performance Thin-Layer Chromatographic Methods for the Determination of Fosinopril Sodium, Hydrochlorothiazide, and Chlorothiazide as Hydrochlorothiazide Impurity", JPC-Journal of Planar Chromatography-Modern TLC, 32(5), 411-420, 2019.

[3] K. Thanki, P. Gangwal, T. Sangamwar, S. Jain, "Oral delivery of anticancer drugs: challenges and opportunities". Journal of controlled release, 170(1), 15-40, 2013.

[4] R. Sawant, L. Bhangale, R. Joshi, P. Lanke, "Validated spectrophotometric methods for simultaneous estimation of Paracetamol, Domperidone and Tramadol $\mathrm{HCl}$ in pure and tablet dosage form". Journal of chemical metrology, 4(1), 21, 2010.

[5] L. Stankevičiūtè, "Nesteroidinių vaistų nuo uždegimo mišinio tyrimas taikant chromatografinius analizės metodus", 2015.

[6] K. Agrawal, K. Shivramchandra, "Spectrophotometric determination of diclofenac sodium in tablets". Journal of pharmaceutical and biomedical analysis, 9(2), 97-100, 1991.

[7] W. Ali, "Different spectrophotometric and TLC-densitometric methods for determination of two analgesic drugs". Asian Journal of Biomedical and Pharmaceutical Sciences, 2014.

[8] S. Mazurek, R. Szostak, "Quantitative determination of diclofenac sodium and aminophylline in injection solutions by FT-Raman spectroscopy". Journal of pharmaceutical and biomedical analysis, 40(5), 12351242,2006

[9] L. Carreira, M. Rizk, Y. El-Shabrawy, A. Zakhari, S. Toubar, "Europium (III) ion probe spectrofluorometric determination of diclofenac sodium". Journal of pharmaceutical and biomedical analysis, 13(11), 1331$1337,1995$.

[10] A. Castillo, L. Bruzzone, "Indirect fluorometric determination of diclofenac sodium". Analytical Sciences, 
22(3), 431-433, 2006.

[11] N. Rashid, H. Bakir, O. Baban, "Spectrophotometric determination of Diclofenac Sodium in pure form and in the pharmaceutical preparations”. Tikrit Journal of Pure Science, 21(3), 76-80, 2018.

[12] J. Sawchuk, A. Maloney, L. Cartier, J. Rackley, K. Chan, S. Lau, "Analysis of diclofenac and four of its metabolites in human urine by HPLC”. Pharmaceutical research, 12(5), 756-762, 1995.

[13] F. Khan, I. Ahmad, M. Akhtar, A. Rauf, H. Altaf, M. Hayat, "RP-HPLC method development and validation for simultaneous determination of esomeprazole and diclofenac sodium in pharmaceutical dosage forms". Pharmaceutical Chemistry Journal, 49(11), 788-794, 2016.

[14] R. Ahmed, N. Lottfi, "High Performance Liquid Chromatographic Method for the determination of Diclofenac sodium in pharmaceutical preparations and in Environmental Samples”. Iraqi National Journal of Chemistry, (44), 467-473, 2011.

[15] M. Davies, E. Anderson, "Clinical pharmacokinetics of diclofenac". Clinical pharmacokinetics, 33(3), 184213, 1997.

[16] W. Jin, J. Zhang, "Determination of diclofenac sodium by capillary zone electrophoresis with electrochemical detection”. Journal of Chromatography A, 868(1), 101-107, 2000.

[17] E. Abdel-Hamid, L. Novotny, H. Hamza, "Determination of diclofenac sodium, flufenamic acid, indomethacin and ketoprofen by LC-APCI-MS". Journal of pharmaceutical and biomedical analysis, 24(4), 587-594, 2001.

[18] A. Saleh, F. Askal, "Spectrophotometric determination of certain local anaesthetics in pharmaceutical preparations". Analytical letters, 28(15), 2663-2671, 1995.

[19] Ö, Aksu, A. Bozdoğan, G. Kunt, "Simultaneous determination of mepyramine maleate, lidocaine hydrochloride, and dexpanthenol in pharmaceutical preparations by partial least-squares multivariate calibration". Analytical letters, 39(4), 751-761, 2006.

[20] W. Holt, Y. Loizou, K. Wyse, "Gas-liquid chromatographic measurement of lignocaine in small samples of canine myocardium after enzymatic digestion". Journal of clinical pathology, 32(3), 225-228, 1979.

[21] W. Ali, S. Abdelwahab, M. Abdelkawy, M. Elgebaly, "Different spectrophotometric and TLC-densitometric methods for determination of diclofenac Na and lidocaine HCl”. Beni-Suef, Cairo, Egypt, 3(6), 57-64, 2013.

[22] S. Liawruangrath, B. Liawruangrath, P. Pibool, "Simultaneous determination of tolperisone and lidocaine by high performance liquid chromatography". Journal of pharmaceutical and biomedical analysis, 26(5-6), 865$872,2001$.

[23] A. Malenovic, M. Medenica, D. Ivanovic, B. Jancic, S. Markovic, "Development and validation of RPHPLC method for cetrimonium bromide and lidocaine determination". Il Farmaco, 60(2), 157-161, 2005.

[24] W. Cao, J. Liu, H. Qiu, X. Yang, E. Wang, "Simultaneous determination of tramadol and lidocaine in urine by end-column capillary electrophoresis with electrochemiluminescence detection". Electroanalysis: An International Journal Devoted to Fundamental and Practical Aspects of Electroanalysis, 14(22), 1571-1576, 2002 .

[25] S. El-Saharty, M. Refaat, Z. El-Khateeb, "Simultaneous determination of diclofenac sodium and diflunisal" Bull Fac Pharm Cairo Univ, 40, 47-64, 2002.

[26] A. Gottschalk, N. Raja, "Severing the Link between Acute and Chronic PainThe Anesthesiologist's Role in Preventive Medicine". Anesthesiology: The Journal of the American Society of Anesthesiologists, 101(5), 1063-1065, 2004.

[27] J. Pavlin, C. Chen, A. Penaloza, L. Polissar, P. Buckley, "Pain as a factor complicating recovery and discharge after ambulatory surgery". Anesthesia \& Analgesia, 95(3), 627-634, 2002.

[28] L. Apfelbaum, C. Chen, S. Mehta, J. Gan, "Postoperative pain experience: results from a national survey suggest postoperative pain continues to be undermanaged”. Anesthesia \& Analgesia, 97(2), 534-540, 2003.

[29] L. Vigneault, F. Turgeon, D. Côté, F. Lauzier, R. Zarychanski, L. Moore, A. Fergusson, "Perioperative intravenous lidocaine infusion for postoperative pain control: a meta-analysis of randomized controlled trials". Canadian Journal of Anesthesia/Journal canadien d'anesthésie, 58(1), 22-37, 2011.

[30] R. Khoshayand, H. Abdollahi, A. Ghaffari, M. Shariatpanahi, H. Farzanegan, "Simultaneous spectrophotometric determination of paracetamol, phenylephrine and chlropheniramine in pharmaceuticals using chemometric approaches". Daru: journal of Faculty of Pharmacy, Tehran University of Medical Sciences, 18(4), 292, 2010.

[31] L. Vigneault, F. Turgeon, D. Côté, F. Lauzier, R. Zarychanski, L. Moore, A. Fergusson, "Perioperative intravenous lidocaine infusion for postoperative pain control: a meta-analysis of randomized controlled trials". Canadian Journal of Anesthesia/Journal canadien d'anesthésie, 58(1), 22-37, 2011.

[32] R. Khoshayand, H. Abdollahi, A. Ghaffari, M. Shariatpanahi, H. Farzanegan, "Simultaneous spectrophotometric determination of paracetamol, phenylephrine and chlropheniramine in pharmaceuticals using chemometric approaches". Daru: journal of Faculty of Pharmacy, Tehran University of Medical Sciences, 18(4), 292, 2010

[33] U. Gasanov, D. Hughes, M. Hansbro, "Methods for the isolation and identification of Listeria spp. and Listeria monocytogenes: a review". FEMS microbiology reviews, 29(5), 851-875, 2005.

[34] Bhusal, P., Sharma, M., Harrison, J., Procter, G., Andrews, G., Jones, D.S., Hill, A.G. and Svirskis, D., 2017. Development, validation and application of a stability indicating HPLC method to quantify lidocaine from polyethylene-co-vinyl acetate (EVA) matrices and biological fluids. Journal of chromatographic science, 55(8), pp.832-838

[35] Belal, T.S., Bedair, M.M., Gazy, A.A. and Guirguis, K.M., 2015. Validated selective HPLC-DAD method for the simultaneous determination of diclofenac sodium and lidocaine hydrochloride in presence of four of their related substances and potential impurities. Acta Chromatographica, 27(3), pp.477-493. 